bioRxiv preprint doi: https://doi org/10.1101/2021.08.04.455049; this version posted August 13,2021 . The copyright holder for this preprint (which was not certified by peer review) is the author/funder, who has granted bioRxiv a license to display the preprint in perpetuity. It is made available under aCC-BY-NC-ND 4.0 International license.

\title{
Helical Ordering of Envelope Associated Proteins and Glycoproteins in Respiratory Syncytial Virus Filamentous Virions
}

Michaela J. Conley ${ }^{1}$, Judith M. Short², Joshua Hutchings ${ }^{3,5}$, Andrew M. Burns ${ }^{1}$, James Streetley ${ }^{1}$, Saskia E. Bakker $^{1,6}$, Hussain Jaffery ${ }^{1}$, Murray Stewart ${ }^{2}$, B. Joanne Power ${ }^{1,7}$, Giulia Zanetti ${ }^{3}$, Rachel Fearns ${ }^{4}$, Swetha Vijayakrishnan ${ }^{1 *}$ and David Bhella ${ }^{1 *}$

\begin{abstract}
Human respiratory syncytial virus (RSV) causes severe respiratory illness in children and the elderly. Treatments for RSV disease are however limited and efforts to produce an effective vaccine have so far been unsuccessful. Understanding RSV virion structure is an important prerequisite for developing interventions to treat or prevent infection but has been challenging because of the fragility of virions propagated in cell culture. Here we show, using cryogenic electron microscopy (cryoEM) and cryogenic electron tomography (cryoET) of RSV particles cultivated directly on transmission electron microscopy (TEM) grids, that there is extensive helical symmetry in RSV filamentous virions. We have calculated a $16 \AA$ resolution three-dimensional reconstruction of the viral envelope, targeting the matrix protein (M) that forms an endoskeleton below the viral membrane. These data define a helical lattice of M proteins, showing how $\mathrm{M}$ is oriented relative to the viral envelope and that helical ordering of viral glycoproteins that stud the viral envelope is coordinated by the $\mathrm{M}$ layer. Moreover, the helically ordered viral glycoproteins in RSV filamentous virions cluster in pairs, which may have implications for the conformation of fusion $(F)$ glycoprotein epitopes that are the principal target for vaccine and monoclonal antibody development. We also report the presence, in authentic virus infections, of N-RNA rings packaged within RSV filamentous virions. Overall, the structural data obtained provides molecular insight into the organization of the virion and the mechanism of its assembly.
\end{abstract}

\section{Introduction}

Respiratory syncytial virus (RSV) causes acute lower respiratory tract disease in infants and the elderly. It is estimated that there are approximately 33 million RSV infections annually in children under the age of five years, leading to around 3 million hospital admissions and 60,000 in-hospital deaths. The great majority of these cases ( $\sim 30$ million) occur in low- and middle-income countries ${ }^{1}$. Although less common than seasonal influenza virus infection, RSV has been shown to be associated with higher mortality rates in hospitalised elderly patients ${ }^{2,3}$.

RSV is formally classified as Human orthopneumovirus within the Orthopneumovirus genus, Pneumovirus family and Mononegavirales order ${ }^{4}$. Closely related to RSV within the Pneumoviridae, in the Metapneumovirus genus is another notable pathogen, human metapneumovirus (HMPV) that also causes bronchiolitis and pneumonia in infants ${ }^{5}$. Thus, both ortho- and metapneumoviruses are clinically important respiratory pathogens.

1. Medical Research Council - University of Glasgow Centre for Virus Research, Sir Michael Stoker Building, Garscube Campus, 464 Bearsden Road, Glasgow G61 1QH UK

2. Medical Research Council Laboratory of Molecular Biology, Francis Crick Avenue, Cambridge Biomedical Campus, Cambridge CB2 0QH, UK

3. Department of Biological Sciences, Department of Biological Sciences, Birkbeck College, Malet St, London, WC1E 7HX, UK

4. Department of Microbiology, Boston University School of Medicine; National Emerging Infectious Diseases Laboratories, Boston University, Boston, Massachusetts, USA

5. Current address Division of Biological Sciences, University of California San Diego, La Jolla, CA, USA

6. Current address School of Life Sciences, University of Warwick, Gibbet Hill Road, Coventry, CV4 7AL, UK

7. Current address Department of Biochemistry and Molecular Biology, The Huck Center for Malaria Research, Pennsylvania State University, University Park, PA 16802, USA

* Corresponding authors.

Email - David.bhella@glasgow.ac.uk, Swetha.Vijayakrishnan@glasgow.ac.uk 
bioRxiv preprint doi: https://doi.org/10.1101/2021.08.04.455049; this version posted August 13,2021 . The copyright holder for this preprint (which was not certified by peer review) is the author/funder, who has granted bioRxiv a license to display the preprint in perpetuity. It is made available under aCC-BY-NC-ND 4.0 International license.

RSV is a non-segmented negative sense RNA containing enveloped virus. The viral genome is $15.2 \mathrm{~kb}$ and has ten open reading frames encoding at least eleven gene products. The viral RNA is encapsidated by multiple copies of the viral encoded nucleocapsid protein $(\mathrm{N})$ to form a left-handed helical ribonucleoprotein complex (or nucleocapsid - NC). This serves as the template for RNA synthesis by the RNA dependent RNA polymerase $(\operatorname{RdRp})^{6,7}$, thought to occur in virus induced cytoplasmic organelles called inclusion bodies ${ }^{8,9}$. The RdRp comprises two proteins: the catalytic large $(L)$ protein and the phosphoprotein $(P)$ that mediates the interaction with the $\mathrm{NC}^{10}$. RNA synthesis is also modulated by the M2 gene products M2-1 and M2$2^{11,12}$. RSV encodes four envelope associated proteins, of which three are membrane proteins: the small hydrophobic protein $(\mathrm{SH})$, fusion protein $(\mathrm{F})$ and attachment protein $(\mathrm{G})$. Underlying the envelope is the fourth envelope associated protein - the matrix protein $(\mathrm{M})$, which coordinates virion assembly together with M2-1. M2-1 forms a second layer at the virion interior, under the M-layer, and associates with NCs ${ }^{13,14}$. High resolution structures for some of the envelope associated proteins of both RSV and HMPV have been determined by X-ray crystallography, including the matrix proteins ${ }^{15-17}$ the $\mathrm{F}$ glycoprotein ${ }^{18,19}$ and $\mathrm{M} 2-1^{20,21}$.

At present, 39 vaccines and monoclonal antibodies (mAbs) targeting RSV are in development, the vast majority of which are directed at two conformations of the RSV F glycoprotein; pre-fusion and post-fusion, and their most neutralization-sensitive antigenic sites, $\varnothing$ and $\mathrm{V}^{22}$. The RSV pre-fusion conformation of the $\mathrm{F}$ glycoprotein is the predominant form displayed at the virion surface and mediates viral entry by fusing viral and host cell membranes. The shapes of enveloped virions and the organization of their surface glycoproteins can impact virus biology by affecting fusion processes ${ }^{23}$, mucus penetration ${ }^{24}$ and complement activation ${ }^{25}$. A comprehensive understanding of RSV virion structure will therefore inform development of effective interventions to prevent RSV disease. Although the structures of RSV proteins and glycoproteins are becoming increasingly well understood, placing these structures in the context of the virion remains challenging, owing to the highly pleomorphic nature of virus particles purified from cellculture $^{13,14}$. Schematic diagrams mostly represent the RSV virion as a spherical particle, it has however, long been known to form predominantly filamentous virions at the assembly site ${ }^{26}$. We have previously shown that propagating filamentous enveloped viruses in cells grown directly on transmission electron microscopy grids leads to improved preservation for imaging by cryogenic electron microscopy (cryoEM) ${ }^{27}$. Here we employ this approach to image RSV filamentous virions by cryoEM and cryogenic electron tomography (cryoET). We show that although RSV virions are prone to loss of integrity, they are nonetheless highly ordered. Fourier analysis shows that filamentous particles exhibit helical symmetry. CryoET combined with sub-tomogram averaging led to the calculation of a three-dimensional density map of the viral matrix layer at $16 \AA$ resolution. Fitting the $\mathrm{X}$-ray structure of $\mathrm{M}$ shows a curved lattice of dimers that closely matches the arrangement seen in the (010) plane of the published X-ray structure (that is, the plane containing the a and $c$ axes of the $C 2$ unit cell). Our model orients the X-ray data relative to the virion filament axis and the viral envelope, providing a view of how $\mathrm{M}$ coordinates virion assembly. Our data also show that the matrix layer coordinates helical ordering of the viral glycoprotein spikes on the virion exterior. Finally, we show that glycoprotein spikes cluster in pairs on filamentous virions but can also pack in an alternate lattice in nonfilamentous virions. Our data also demonstrate the presence of an abundance of ring-shaped assemblies, likely formed of the nucleocapsid protein N and RNA. Our findings concerning the structure of RSV provide a molecular understanding of virion organisation and assembly, information that is critically important in the development of effective vaccines or interventions to prevent or treat this major respiratory pathogen.

\section{Results}

CryoEM of filamentous RSV virions reveals helical order

To image RSV filamentous virions in as close to native conditions as possible we propagated virus in cells cultured directly on holey carbon support films. Over the course of our investigations several cell types were used - Vero (African green monkey kidney cells), U-2 OS (human osteosarcoma cells) and A549 (human adenocarcinoma cells). All were found to be suited to imaging filamentous virions. Imaging of filaments was optimal at 72 hours post-infection (fig 1A). Cryo-EM grids were therefore prepared by plunge-freezing at this time-point. Initial imaging of virus propagated in U2-OS and Vero cells in a JEOL 2200 FS cryomicroscope revealed well preserved filamentous virions, although it was clear that they are prone to physical disruption (fig S1A). Power spectra calculated from cropped sections of filamentous virions indicated a high degree of 
bioRxiv preprint doi: https://doi.org/10.1101/2021.08.04.455049; this version posted August 13,2021 . The copyright holder for this preprint (which was not certified by peer review) is the author/funder, who has granted bioRxiv a license to display the preprint in perpetuity. It is made available under aCC-BY-NC-ND 4.0 International license.
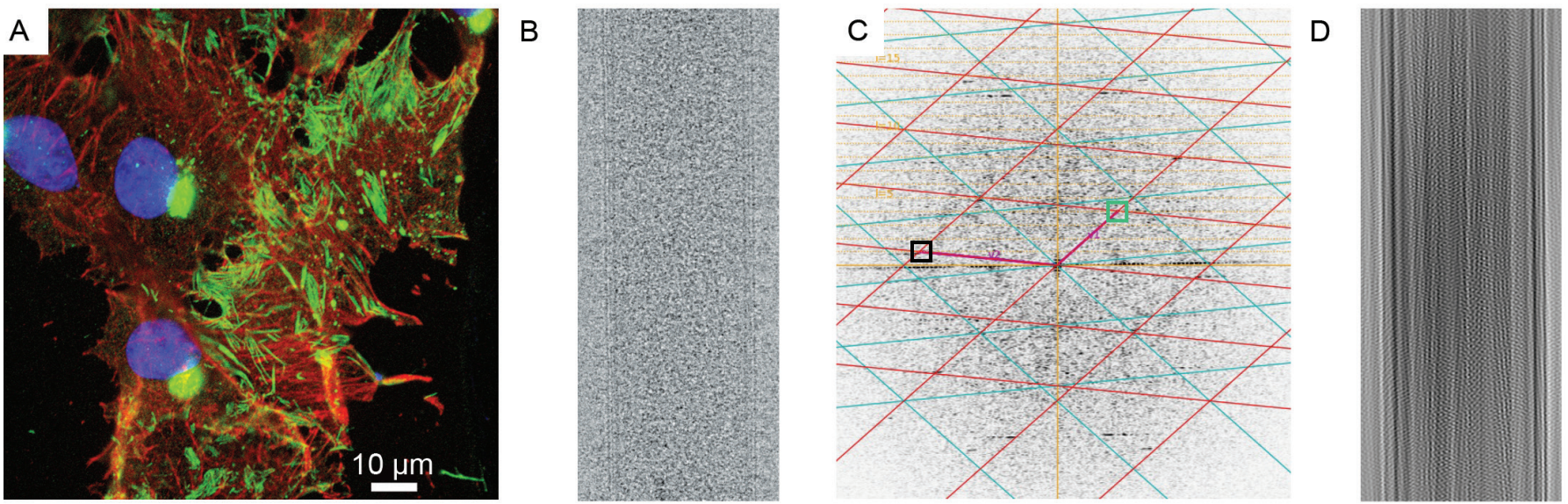

Figure 1. Respiratory syncytial virus forms filamentous virions that exhibit a high degree of helical order. (A) Immunofluorescence imaging of vero cells infected with RSV at 72 hours post-infection shows an abundance of filamentous particles. Virus particles were identified by labelling with an antibody that targeted the nucleocapsid protein (green). Phalloidin was used to localise actin (red) and DAPI reagent was used to stain cell nuclei (blue). (B) CryoEM image of a short section of RSV filament. (C) The power-spectrum for the filament shown in (B) is shown, Fourier-Bessel analysis was used to identify a putative helical lattice, the positions of principal maxima are indicated by boxes, however one was found to be missing (green box). The lattice was only able to be identified using higher-order reflections. (D) Masking and Fourier synthesis led to the reconstitution of a filtered image, showing that although a helical lattice is present, it is not sufficiently ordered to show features along the full length of the filament.

helical order evidenced by the presence of multiple layer-lines (fig S1B-C). To collect images better suited to Fourier analysis, RSV virions produced in U2-OS cells were imaged in a Thermo-Fisher Titan Krios 300 $\mathrm{keV}$ cryomicrocope, equipped with a Falcon II direct electron detector (fig 1B). The diameters of filaments extracted from these images varied considerably and spanned a range of $900-1600 \AA$. Fourier transforms (fig. 1C) showed patterns of layer lines consistent with helical symmetry. Indexing of the transforms using the program PyHI (personal communication Xuewu Zhang - University of Texas Southwestern Medical Center) suggested that the Bessel orders of the two principal maxima were very large, consistent with the tubes being constructed of many helical strands, probably of the order of 50 . Helical objects such as these can be thought of as crystalline sheets that have been rolled up to form a tube ${ }^{28}$ and in a helix with this symmetry the units would lie on a lattice that can be specified by the two vectors indicated by the principal maxima, one of which had a length of $\sim 86 \AA$ aligned at $\sim 85^{\circ}$ to the helix axis and the second had a length of $\sim 51 \AA$ and aligned at $\sim 49^{\circ}$ to the helix axis. There was no density for the principal maximum for this second vector, the lattice was however established by using higher order reflections. Although the filtered image (Fig 1D) showed many areas where an indication of the underlying lattice of subunits could be discerned, the local lattices were only clear in limited areas, presumably a consequence of local distortions. This, together with the relatively weak intensity of the transforms and the large radii of the principal maxima frustrated the production of reliable 3-dimensional reconstructions using Fourier-Bessel methods. Such problems are often seen with helical tubes containing large numbers of strands ${ }^{29}$ and led us to explore whether cryo-ET could provide a structure of the underlying lattice.

\section{Cryo-ET of RSV filamentous virions}

To resolve the helical lattices underpinning RSV virion structure and assembly, we used cryogenic electron tomography to calculate three-dimensional reconstructions of individual virions. Fifty-eight tilt series were recorded on a Thermo-Fisher Titan Krios $300 \mathrm{keV}$ cryomicroscope equipped with a Gatan K2 bioquantum energy filtered direct electron detector. Tilt-series' of images were collected specifically targeting straight, undisrupted segments of filamentous virions. Low-magnification views of regions selected showed that although filamentous structure was well preserved by culturing virus on the TEM grid (fig 2A), many virions were to some extent disrupted, frequently having varicosities at points along their length or at one end. These data confirm that RSV virions are very fragile and easily lose their filamentous shape (fig 2B-C). 
bioRxiv preprint doi: https://doi.org/10.1101/2021.08.04.455049; this version posted August 13, 2021. The copyright holder for this preprint (which was not certified by peer review) is the author/funder, who has granted bioRxiv a license to display the preprint in perpetuity. It is made available under aCC-BY-NC-ND 4.0 International license.

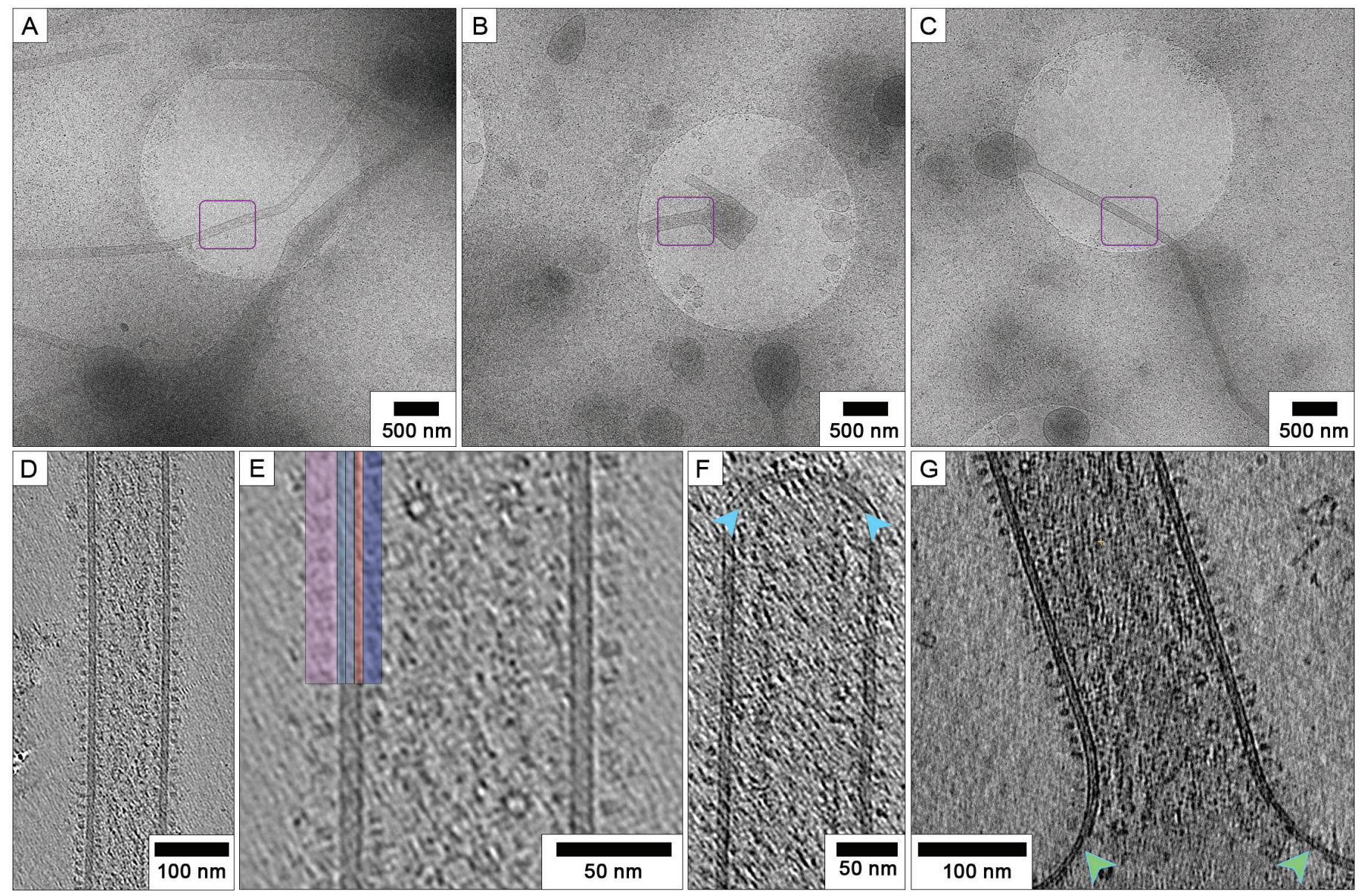

Figure 2. Cryoelectron tomography of RSV filaments reveals a complex envelope. (A) propagating RSV directly on the TEM grid led to improved preservation of filamentous morphology. $(B, C)$ Despite the gentle preparation methods, many virions showed signs of disruption such as varicosities. The areas indicated by purple boxes were imaged to collect tilt-series'. The filament in panel $A$ is shown in figure $3 A$, the filament in panel $B$ is shown in figure $2 G$ and the filament shown in panel $C$ is shown in figure $3 B$. (D) a central slice through a denoised tomogram shows a complex viral envelope, shown at higher magnification in $(E)$. Glycoprotein spikes are densely packed, giving a picket-fence like appearance when viewed from the side (highlighted in mauve). The lipid bilayer is highlighted in pale blue, the matrix layer in orange and the M2-1 layer in dark blue. (F) tilt-series' were collected targeting straight regions of filamentous virions, however some tomograms captured the virion ends, which were found to be hemispherical but rather flattened. In some cases (as shown here) the matrix layer was intact and contiguous at the filament ends (blue arrows), while some virions showed an absence of $M$. (G) Loss of virion integrity was accompanied by discontinuities in the matrix layer (green arrows).

\section{A complex, ordered viral envelope}

Tomographic reconstruction of filament sections reveal that they are well-ordered. As previously reported ${ }^{13,14,30}$, we find that the viral envelope is densely packed with viral glycoprotein spikes. Underlying the lipid bilayer is a contiguous density that we attribute to the matrix protein (M). This gives the viral envelope the appearance of being triple layered (fig 2D-E, movie S1 timepoint $0 \mathrm{~m} \mathrm{25s).} \mathrm{Beneath} \mathrm{the} \mathrm{M-layer,} \mathrm{is} \mathrm{a} \mathrm{second} \mathrm{less} \mathrm{sharply}$ defined protein layer that has previously been attributed to the M2-1 protein ${ }^{13}$. Filament ends were typically hemispherical having a large radius of curvature, lending the caps a flattened appearance. Most tomograms of virion ends showed a contiguous matrix layer (fig $2 \mathrm{~F}$ ), although some were seen to have disrupted or missing matrix layers. Discontinuity in the matrix layer was more apparent in the varicose areas, indicating that loss of virion integrity is likely a consequence of detachment or mis-assembly of the matrix layer (fig $2 \mathrm{G})$.

\section{Nucleocapsids appear as classical herringbone assemblies, loosely coiled helices and rings}

The virion interior is densely packed with viral nucleocapsids, mainly having the characteristic herringbone morphology ${ }^{31}$ and suggesting that in common with several other mononegavirales, RSV virions are polyploid ${ }^{32}$ (fig $3 \mathrm{~A}$, movie $\mathrm{S} 1$ timepoint $1 \mathrm{~m} \mathrm{08s).} \mathrm{Virions} \mathrm{were} \mathrm{also} \mathrm{seen} \mathrm{to} \mathrm{be} \mathrm{filled} \mathrm{with} \mathrm{an} \mathrm{abundance} \mathrm{of} \mathrm{ring-like}$ 

made available under aCC-BY-NC-ND 4.0 International license.
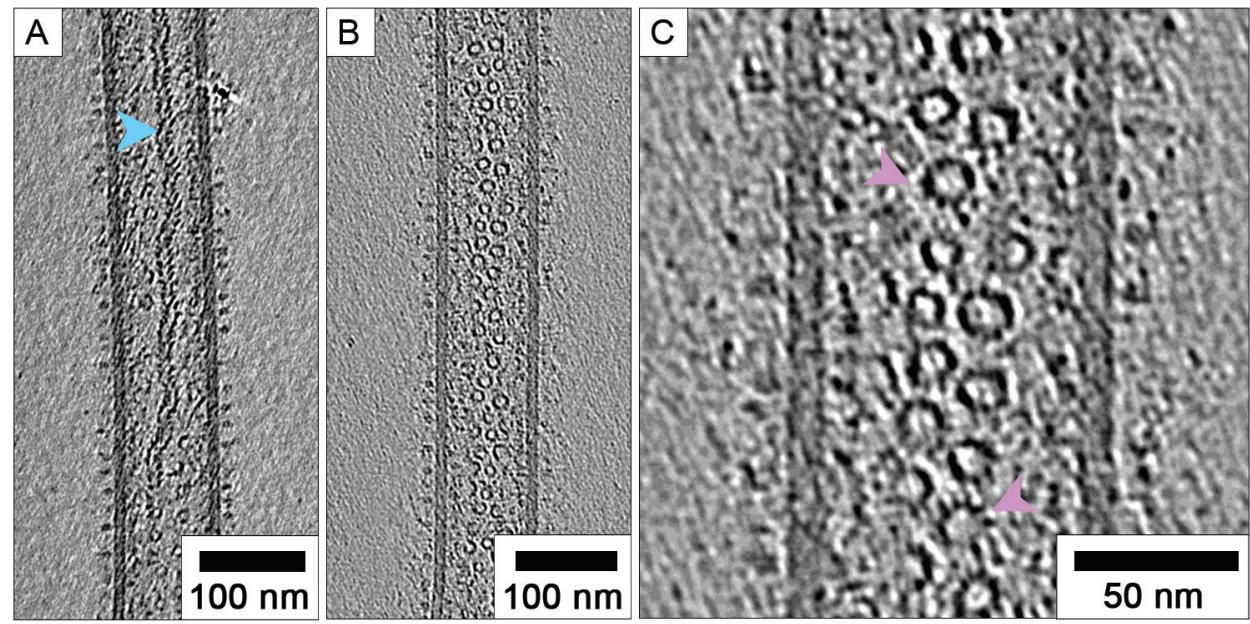

Figure 3. RSV virions package helical nucleocapsids and an abundance of N-RNA rings. (A) central slices through tomograms showed that virions contain multiple nucleocapsids, many having the characteristic herringbone morphology (blue arrow). (B) Many virions also contain large numbers of ring-shaped assemblies. (C) a close-up view of these structures reveals the presence of radial spokes (pink arrows). These structures are morphologically very similar to previously described decameric and undecameric rings produced by recombinant expression of RSV N.

assemblies that ranged in diameter from 10 to $17 \mathrm{~nm}$ (fig 3B). Upon close inspection of these structures, we found several rings that had radial spikes and morphology highly reminiscent of the decameric and undecameric rings produced by heterologous expression of the RSV N protein in insect cells or bacteria 7,31,33,34 (fig 3C movie S1 timepoint 1m 30s). In some cases, these ring-like features appeared to precess, when moving through successive sections of tomograms, whereas in others there was no obvious continuity of density (movie S1 timepoint $2 \mathrm{~m} 20 \mathrm{~s}$ ). We hypothesise then that some of these ring-shaped assemblies are likely loosely coiled NC, but the absence of connecting density in successive tomogram sections and the presence of some isolated rings outside the virions (suspended in the vitreous ice layer - movie S1 timepoint $2 \mathrm{~m} \mathrm{05s)} \mathrm{strongly} \mathrm{suggest} \mathrm{that} \mathrm{many} \mathrm{of} \mathrm{these} \mathrm{objects} \mathrm{may} \mathrm{indeed} \mathrm{be} \mathrm{N-RNA} \mathrm{rings,} \mathrm{perhaps} \mathrm{being} \mathrm{products}$ of aborted genome replication. 
bioRxiv preprint doi: https://doi.org/10.1101/2021.08.04.455049; this version posted August 13, 2021. The copyright holder for this preprint (which was not certified by peer review) is the author/funder, who has granted bioRxiv a license to display the preprint in perpetuity. It is made available under aCC-BY-NC-ND 4.0 International license.

Helical ordering, clustering, and hexagonal arrays of glycoproteins

Previous studies have reported that RSV glycoprotein spikes are densely packed, giving a picket-fence appearance when viewed from the side (e.g. fig 2E) ${ }^{13,14,30}$. A significant proportion of our tomograms showed helical ordering of glycoproteins, manifesting as striped arrays of density when viewed as slices taken through the glycoproteins at the top and bottom of virions (Fig 4A, movie S1 timepoint $2 \mathrm{~m} 42 \mathrm{~s}$ ). Measurements of the spacings between the rows of glycoprotein spikes ranged between 89 and $208 \AA$, having both a mean and mode of $135 \AA$ (SD=20.6, n=150). Some virions exhibited extensive and long-range ordering of the glycoproteins. Interestingly, the glycoprotein spikes were often observed to cluster in pairs (fig 4B). This was even more apparent in tomograms of virions that were only sparsely decorated with glycoproteins (fig 4C-F). Centre to centre measurements of the spacing of paired glycoprotein spikes gave a mean distance of $84 \AA$ $(S D=7.9, n=100)$.

An earlier tomogram of RSV infected Vero cells, collected on a JEOL 2200 FS cryomicroscope showed a large membranous structure, that might be interpreted as a pleomorphic virion or cell debris. This object showed angular, thicker regions of membrane, consistent with the presence of a matrix layer (as also seen in fig 2B), picket-fence like arrangement of glycoprotein spikes, and contained both nucleocapsid and ring-shaped assemblies (fig 4G - movie S1 timepoint 3m 22s). This object also had patches of density packed to form a honeycomb lattice (fig $4 \mathrm{H}-\mathrm{I}$ ). The lattice appeared to be contiguous with the side-views of the glycoprotein spikes (movie S1 timepoint 3m 37s) and in places individual densities consistent with single glycoprotein spikes could be seen. Considering the clustering of RSV glycoprotein spikes in pairs described above, we hypothesise that this array is an alternate arrangement of glycoproteins. Making accurate measurements

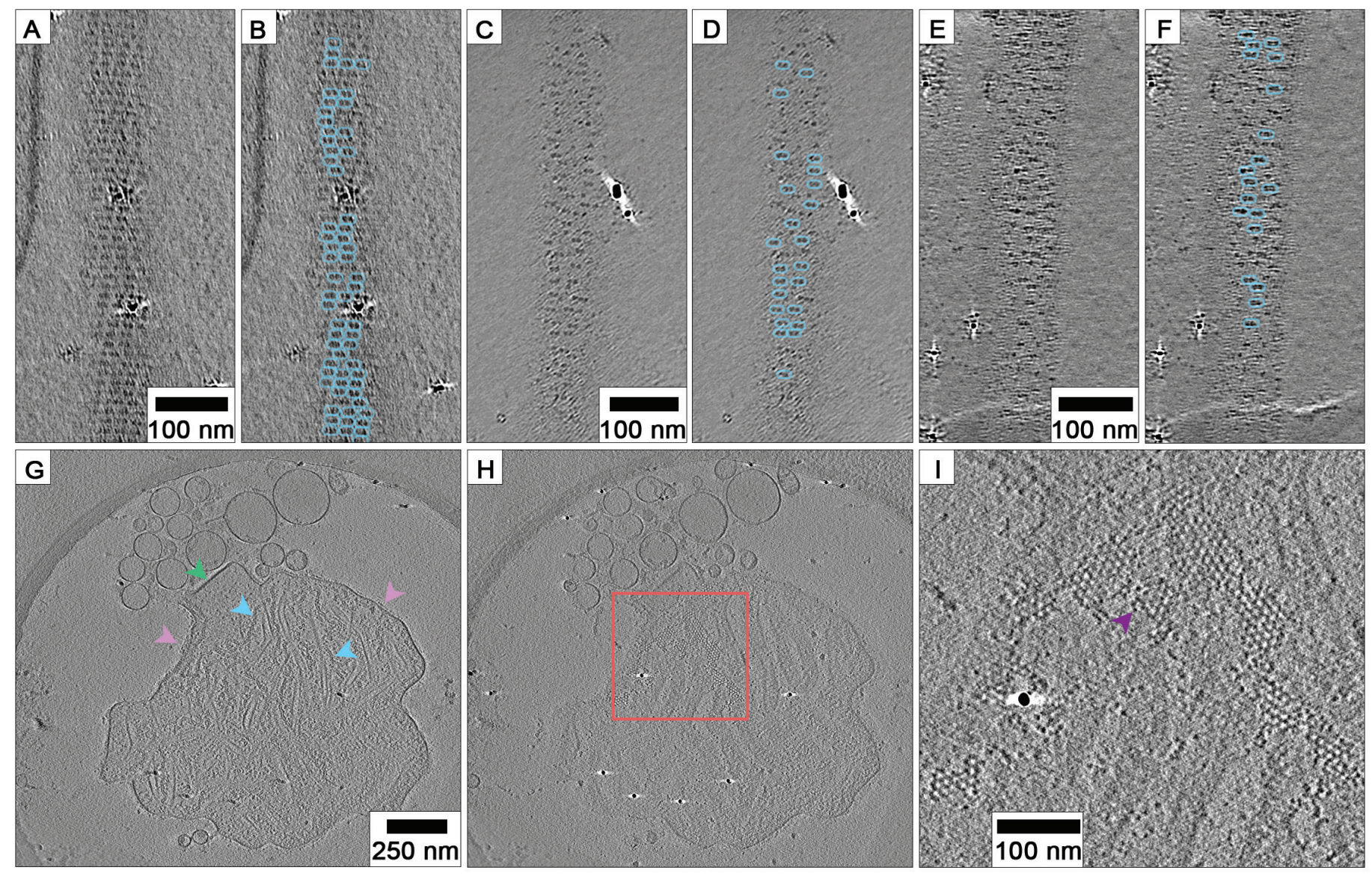

Figure 4. Helical ordering and clustering of RSV glycoprotein spikes. (A) a slice through the glycoprotein spikes of a filamentous RSV virion shows that they are helically ordered. Long range ordering of the glycoprotein spikes is evident, as is clustering of spikes in pairs (highlighted in (B)). (C-F) in virions that are sparsely decorated with glycoprotein spikes, clustering in pairs is even more apparent. (G) a central section through a tomogram of a pleomorphic RSV virion showing the presence of both herringbone nucleocapsids and N-RNA rings (blue arrows), flattened, thicker membranes that likely have a matrix-layer (green arrow), and tightly packed glycoprotein spikes (pink arrows). ( $\mathrm{H}-\mathrm{I})$ a section through the envelope region of the same particle shows the presence of a honeycomb-like array of densities that may be an alternate arrangement of glycoprotein spikes, discrete densities are seen (purple arrow) that are likely individual glycoprotein spikes. 
bioRxiv preprint doi: https://doi.org/10.1101/2021 08.04.455049; this version posted August 13, 2021. The copyright holder for this preprint (which was not certified by peer review) is the author/funder, who has granted bioRxiv a license to display the preprint in perpetuity. It is made available under aCC-BY-NC-ND 4.0 International license.

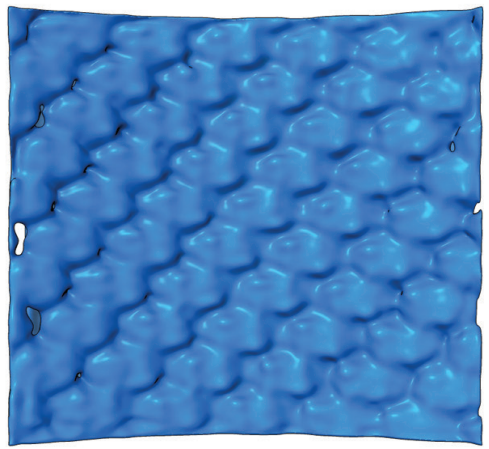

D

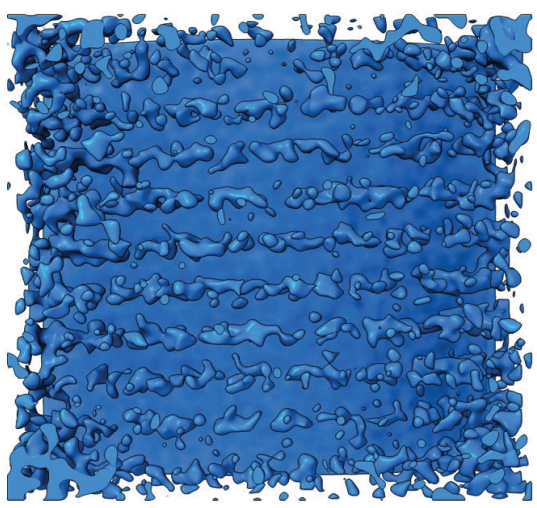

B

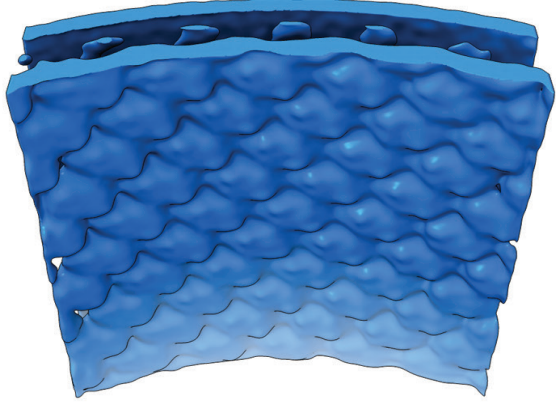

E

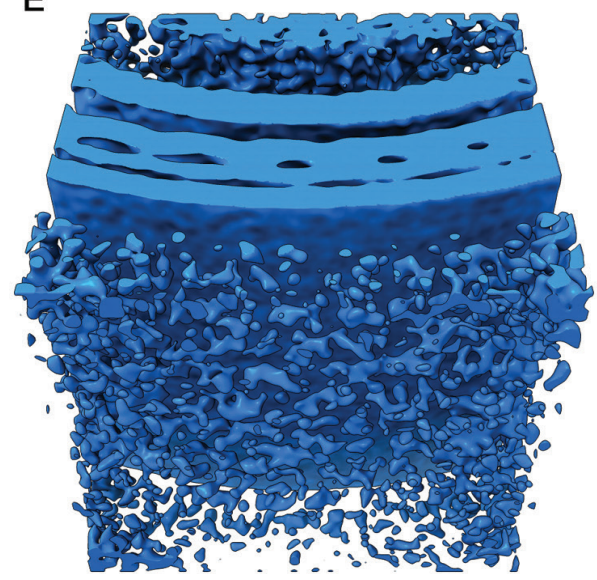

C

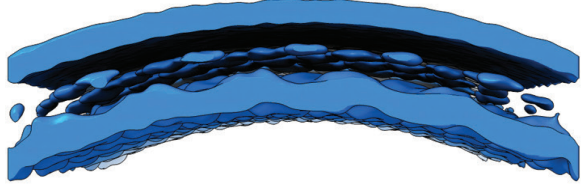

$\mathbf{F}$

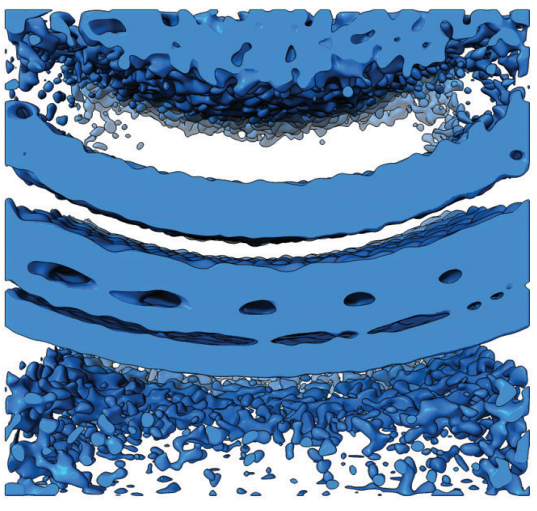

Figure 5. Subtomogram averaging of the RSV viral envelope reveals the structure of the matrix layer. (A) viewed from the filament interior, a regular array of density is seen in the envelope layer attributed to the matrix protein. (B) the average is tilted $45^{\circ}$ towards the viewer. (C) the average is tilted a further $45^{\circ}$, giving a view of the lipid bilayer. The inner leaflet of the bilayer is only weakly resolved compared to the outer leaflet. (D) Viewed from the virion exterior at a lower isosurface threshold, stripes of weak, noisy density are seen. This is likely incoherent averaging of glycoprotein spike density. (E) tilting the reconstruction towards the viewer by $45^{\circ}$ shows that the inner leaflet contacts the M-layer. (F) A fourth density layer is now visible, under the matrix. This density has been previously attributed to the RNA polymerase co-factor M2-1. Like the glycoprotein density at the exterior of the envelope, the M2-1 density is weak and incoherently averaged.

of the lattice was challenging as the densities were mostly not sharply resolved, nonetheless by measuring distances between vertices of hexagons we estimated the mean spacing between glycoprotein spikes to be $74 \AA$ (SD=9.5, $n=50)$.

\section{Sub-tomogram averaging of RSV envelope components - packing of matrix proteins}

To better understand the way the RSV matrix protein drives virion assembly, we sought to calculate a threedimensional reconstruction of the matrix layer by sub-tomogram averaging. Tiles of the viral envelope were extracted and aligned using Dynamo ${ }^{35}$, yielding a 3D reconstruction of the matrix layer at $16 \AA$ resolution (Fig S2). Viewed from the virion interior, the reconstruction reveals a regular array of M proteins (fig 5A-C, movie S2 timepoint $0 \mathrm{~m} \mathrm{7s).} \mathrm{Viewed} \mathrm{from} \mathrm{the} \mathrm{virion} \mathrm{exterior} \mathrm{the} \mathrm{reconstruction} \mathrm{has} \mathrm{weak} \mathrm{stripes} \mathrm{of} \mathrm{density} \mathrm{that}$ are visible at lower isosurface threshold levels (fig 5D-F, movie S2 timepoint $0 \mathrm{~m}$ 32s). This feature is likely incoherent averaging of the viral glycoprotein spikes. 
bioRxiv preprint doi: https://doi.org/10.1101/2021.08.04 455049; this version posted August 13, 2021. The copyright holder for this preprint (which was not certified by peer review) is the author/funder, who has granted bioRxiv a license to display the preprint in perpetuity. It is made available under aCC-BY-NC-ND 4.0 International license.

The X-ray structure and solution studies of the RSV M protein showed that it assembles into dimers ${ }^{15}$ (fig $6 \mathrm{~A}$ $B$, movie S2 timepoint $0 \mathrm{~m} \mathrm{46s).} \mathrm{Interestingly} \mathrm{in} \mathrm{that} \mathrm{study,} \mathrm{the} \mathrm{M} \mathrm{dimers} \mathrm{in} \mathrm{the} \mathrm{C2} \mathrm{crystal} \mathrm{lattice} \mathrm{were} \mathrm{stacked}$ into sheets (fig 6C, movie S2 timepoint 1m 10s). Docking the coordinates of the M-dimer (PDB 4V23) into our map generated a curved array that closely resembled the arrangement seen in the $(a, c)$ plane of the X-ray

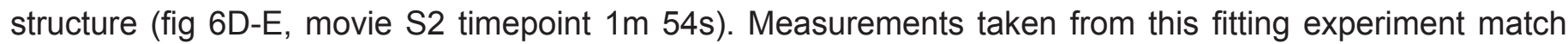
closely those made in our Fourier-Bessel analysis (fig 6F). A low-pitch, right-handed helix follows the $(1,0,-1)$ direction of the $C 2$ unit cell of the X-ray structure, which is the $(1,1)$ direction in the P2 sheet (shown in fig $6 \mathrm{C})$. This had a spacing of $82 \AA$ and an angle of $86.5^{\circ}$ relative to the filament axis. The $a$ and $c$ axes in the C2 X-ray structure unit cell correspond to the long-pitch helical strands having rise and tilt measurements of $54 \AA / 40^{\circ}$ (left-handed) and $66 \AA / 45^{\circ}$ (right-handed) respectively.

A

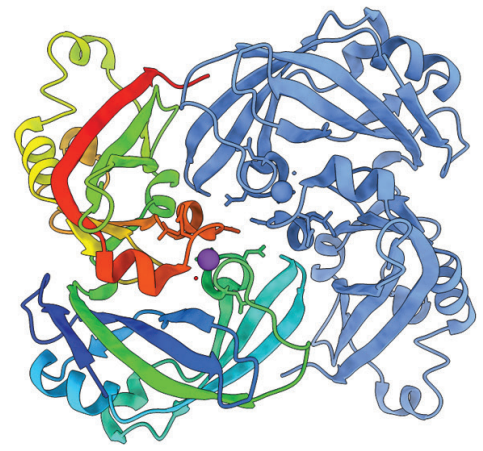

D

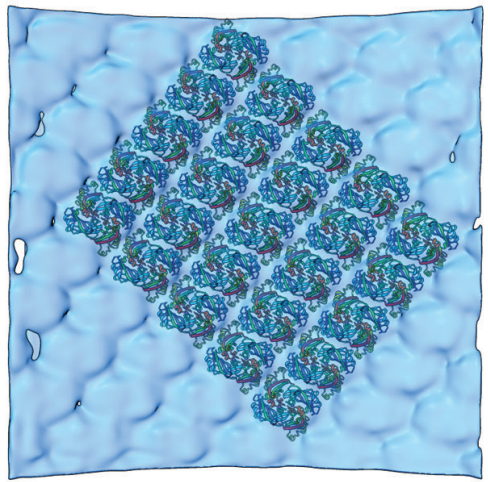

B

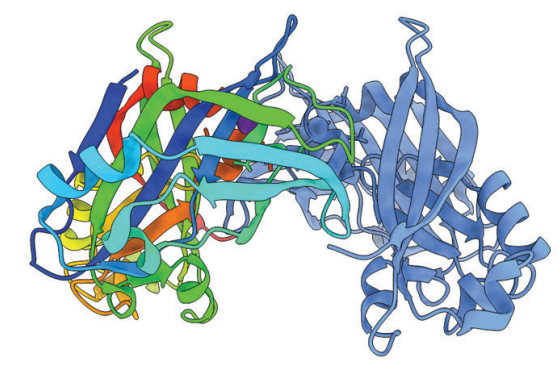

$E$

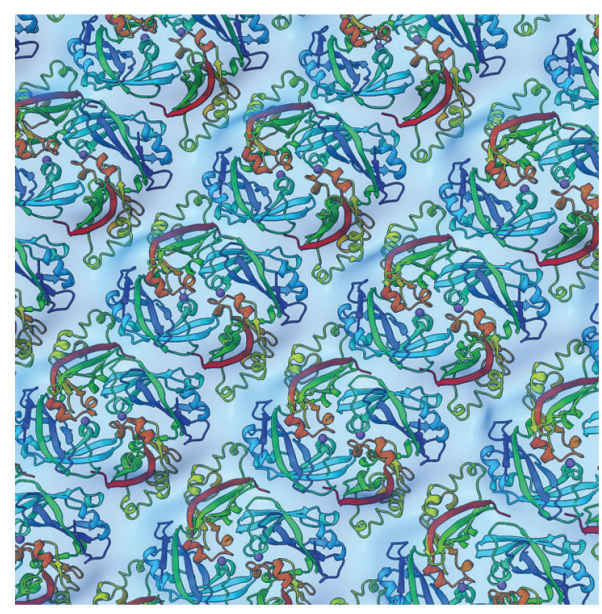

C

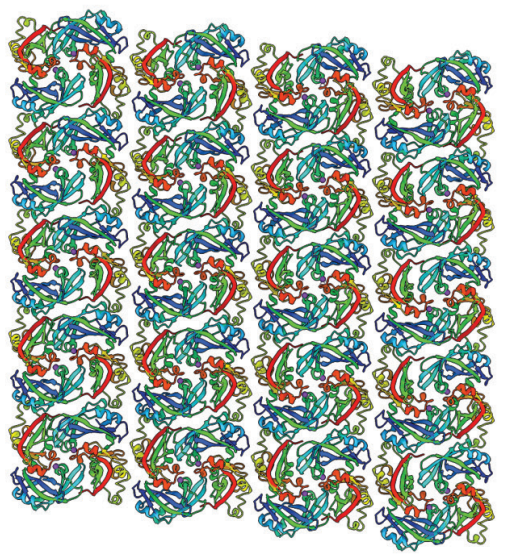

$\mathrm{F}$

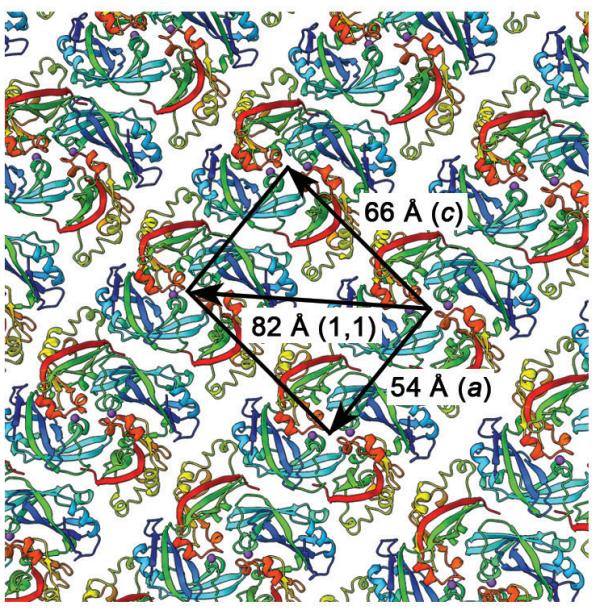

Figure 6. Docking the $X$-ray structure of $M$ into the sub-tomogram average. (A-B) The published X-ray structure for RSV M shows that it forms a dimer (PDB accession number 4V23). (C) In the X-ray structure $\mathrm{M}$ dimers pack as stacked sheets in the (010) plane of the C2 crystals. (D) docking the M-dimer into the 3D reconstruction shows a curved lattice with similar packing in virio to the planar sheets seen in the crystal structure. (E) close up view of the docked M coordinates. (F) Measurements of the lattice spacings of M-dimers in the docked model of the matrix layer. A low-pitch helix corresponding to the $(1,1)$ direction of the planar lattice (shown in panel $\mathrm{C}$ ) has a spacing of $82 \AA$. Helix strands corresponding to the $a$ and $c$ axes in the $C 2$ unit cell of the X-ray structure have spacings of $54 \AA$ and $66 \AA$ respectively.

Our fitted model clearly establishes the orientation of M-dimers relative to the viral envelope allowing the contact surface with the inner-leaflet to be identified (fig 7A). This surface is strongly positively charged (fig 7B-C movie S2 timepoint $2 \mathrm{~m} \mathrm{45s),} \mathrm{whereas} \mathrm{the} \mathrm{interior} \mathrm{surface} \mathrm{of} \mathrm{the} \mathrm{matrix} \mathrm{array} \mathrm{presents} \mathrm{stripes} \mathrm{of}$ negative charge (fig 7D-E, movie S2 timepoint $2 \mathrm{~m} \mathrm{35s}$ ) that may be important in coordinating the packaging of M2-1 and viral nucleocapsids. When considered in the context of the sub-tomogram average viewed at lower isosurface threshold, the stripes of density that we have assigned to the viral glycoprotein spikes align to the array of M-dimers (fig 7F). The spacing of these stripes of density does not however match those in the raw tomograms ( $45 \AA$ versus $135 \AA$ ). These data suggest that the helix of glycoprotein spikes is coordinated by the matrix layer, albeit the array does not exactly follow the underlying lattice of $M$ dimers. Rather, the 
bioRxiv preprint doi: https://doi.org/10.1101/2021.08.04 455049; this version posted August 13, 2021. The copyright holder for this preprint (which was not certified by peer review) is the author/funder, who has granted bioRxiv a license to display the preprint in perpetuity. It is made available under aCC-BY-NC-ND 4.0 International license.

process of aligning sub-tomograms to the lattice of the matrix layer has led to superposition of the more widely spaced array of glycoprotein spikes, leading to these densities appearing to be more closely packed in the sub-tomogram average than they actually are.

A
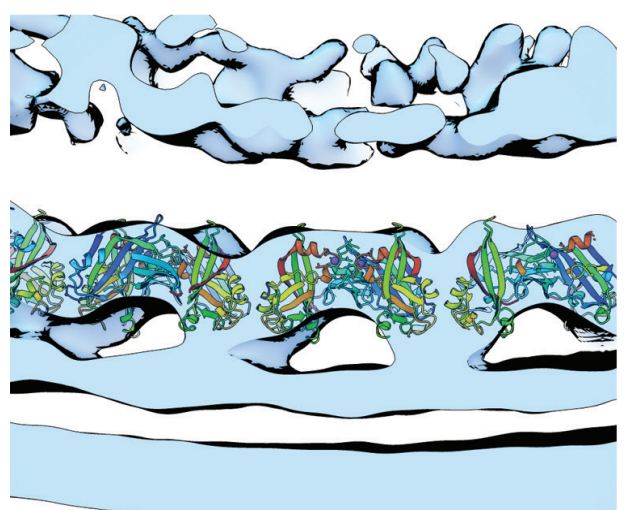

B

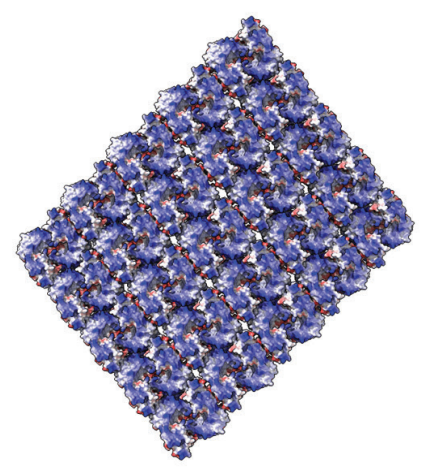

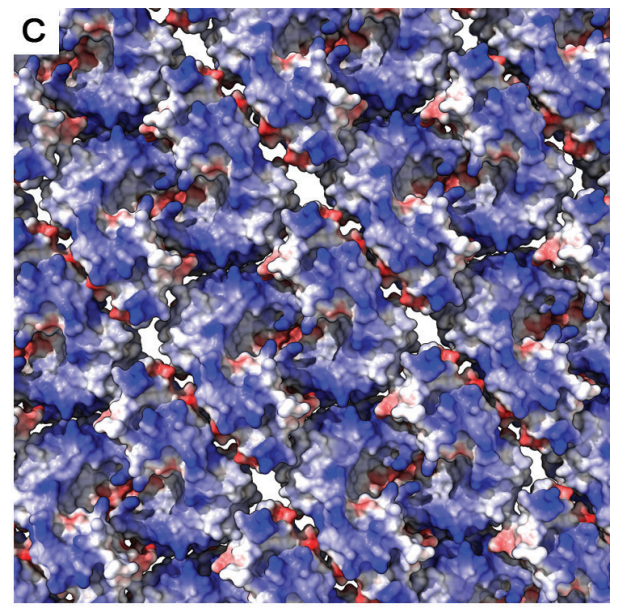
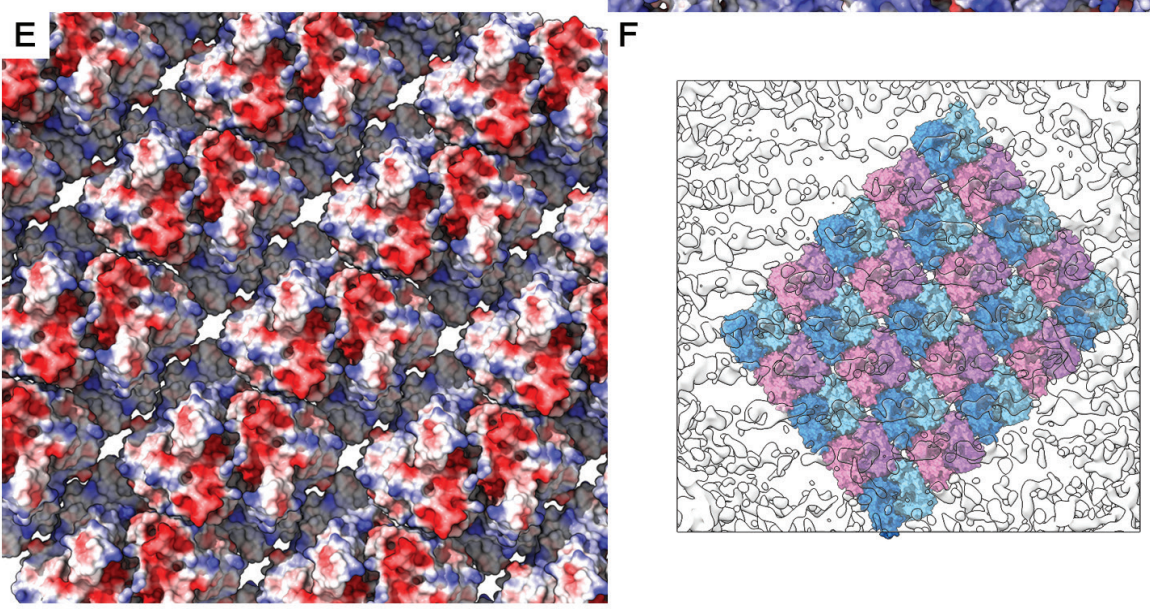

Figure 7. Orienting the matrix layer relative to the viral envelope and glycoproteins. (A) a section through the subtomogram average reconstruction with fitted coordinates for $\mathrm{M}$ shows the orientation of the M-dimer relative to the inner leaflet of the lipid bilayer. (B-C) a solvent excluded surface representation of the matrix layer is presented coloured to show the electrostatic potential. It shows that the surface facing the lipid bilayer is positively charged, while the surface facing the virion interior presents stripes of negative charge (D-E). (F) a view of the docked model placed within a transparent isosurface of the subtomogram average reconstruction and viewed at an isosurface threshold of 0 from the virion exterior shows that the noisy weak density that we attribute to the viral glycoprotein spikes aligns with the $(1,1)$ helix (alternate strands are coloured pink and blue).

\section{Discussion}

We have used cryogenic electron microscopy and tomography to study the structure of filamentous virions of respiratory syncytial virus propagated directly on the transmission electron microscopy support grid. This approach has allowed these large fragile structures to be imaged while minimising disruption caused by sample preparation. These data show that far from being a disordered pleomorphic virion comprising a membranous bag filled with nucleocapsid, RSV assembles highly ordered virions. Fourier analysis demonstrated that virions have extensive helical order. We were able to characterise the extent of this order by 3D imaging of virions using cryo-ET, combined with sub-tomogram averaging.

\section{Nucleocapsid morphology and packaging of N-RNA rings}

Denoised tomograms of RSV filamentous virions revealed an abundance of nucleocapsids packaged within the virions. Many were seen to exhibit the classical herringbone morphology previously described for nucleocapsid-like particles produced by heterologous expression of the RSV N protein ${ }^{6,31,34}$. We also observed large numbers of ring-shaped assemblies. These rings bear a striking resemblance to N-RNA rings also previously described and although rings are produced following heterologous expression of $\mathrm{N}$ proteins 
bioRxiv preprint doi: https://doi.org/10.1101/2021.08.04.455049; this version posted August 13,2021 . The copyright holder for this preprint (which was not certified by peer review) is the author/funder, who has granted bioRxiv a license to display the preprint in perpetuity. It is made available under aCC-BY-NC-ND 4.0 International license.

from a variety of mononegavirales ${ }^{31,36,37}$ we believe that this is the first report of N-RNA rings being produced in authentic virus infections. It is not known what RNA species is associated with virion-associated N-RNA rings. Some of the most abundant RNA species in RSV-infected cells are short 21-25 nt RNAs generated from the leader $(l e)$ and trailer (tr) promoter regions ${ }^{38-40}$. Previous studies have shown that a fraction of these RNAs are nuclease resistant, indicating that they can be encapsidated ${ }^{40}$. Although it is well accepted that N-RNA rings would be expected to contain $70 \mathrm{nt}$ of RNA encapsidated by $10 \mathrm{~N}$ protomers ${ }^{6,7}$, it has been shown that if purified recombinant $\mathrm{N}$ protein is incubated with RNAs as short as $14 \mathrm{nt}$, it can form N-RNA rings that are of similar dimensions as those reconstituted with longer $R N A s^{41}$. This suggests either that RNA is only required to nucleate the encapsidation event and that subsequent $\mathrm{N}-\mathrm{N}$ interactions allow formation of a 10-protomer ring that is not necessarily entirely RNA-bound, and/or that short N-RNA complexes can associate together to form $10 \mathrm{~N}$-protomer rings containing multiple small RNA oligonucleotides. Thus the $\sim 20-25 \mathrm{nt}$ RNAs found in abundance in RSV infected cells could potentially be incorporated into N-RNA rings and packaged into virions. Whether N-RNA rings fulfil a functional role in newly infected cells, such as nucleating liquid-liquid phase separated biomolecular condensates to serve as transcription/ replication centers ${ }^{42,43}$ or inhibiting cellular stress responses ${ }^{44}$ remains to be determined.

\section{Packing of M-dimers in the matrix layer and variations in filament radii}

Fourier analysis of cryoEM images of filamentous virions showed the presence of helical ordering in these particles. The highly variable radii of filamentous virions together with the weak intensity of layer lines and missing principal maxima in the Fourier transforms frustrated our efforts to compute a 3D reconstruction using Fourier-Bessel methods. Nonetheless, these data encouraged us to continue investigating the structure of these important virions using tomography and sub-tomogram averaging. This led to the calculation of a $3 \mathrm{D}$ reconstruction of the viral envelope that showed how M-dimers pack together to form the matrix layer, unequivocally orienting the dimers relative to the inner-leaflet of the lipid bilayer and orienting the $\mathrm{M}$ lattice relative to the virion's filament axis. Docking the X-ray structure to our cryo-EM 3D reconstruction showed that the curved lattice of M-dimers closely matches the planar arrays previously seen in the M crystals. In figure $6 \mathrm{~F}$ we show measurements of vectors along the lattice, a right-handed $(1,1)$ helix with a spacing of 82 $\AA$ between subunits and a left-handed (a) helix with a spacing of $54 \AA$. The axial rise per subunit for each of these helices is approximately $5 \AA$ and $45 \AA$ respectively. If the matrix tube was to polymerise as a simple 1-start, right-handed $(1,1)$ helix then it would comprise 8 helical strands (along the $a$ or $c$ directions) and have a radius of $\sim 100$ angstroms. This is considerably smaller than the measured radii of the matrix layers in our viral filaments, which ranged between 370 and $660 \AA$ (fig S3). Thus, we expect the matrix layers of filamentous virions to exhibit more complex geometries assembling as $n$-start $(1,1)$ helices and incorporating different numbers of helical strands (likely between $\sim 30$ and $\sim 50$ ). The matrix layer can be thought of as a sheet corresponding to the $(a, c)$ plane of the $C 2$ crystal lattice, that has been rolled into a tube. Because the number of helical strands in a filament is large, only small distortions would need to be introduced to bend the sheet to form a cylinder. Indeed, distortions of the M dimer interface that were postulated to foster curvature have been observed ${ }^{15}$. Incorporating different numbers of helical strands in the matrix layer would accommodate the considerable variation in filament diameters that are observed. Although each different number of strands would be associated with different helical parameters, the underlying $\mathrm{M}$ lattice would remain the same.

Helical ordering and clustering of glycoprotein spikes - implications for virion assembly, entry, and the design of interventions to prevent RSV disease.

Our tomograms showed several virions that exhibited clear helical ordering of glycoproteins, features confirmed by sub-tomogram averaging. Measurements of the spacing between successive turns of these helices gave a mean value of $135 \AA$. The spacing between strands of the low-rise right-handed $(1,1)$ helix of $\mathrm{M}$ dimers that coincides with the stripes of density attributed to the glycoprotein spikes in our sub-tomogram average was $45 \AA$ however. This, together with the weak intensity of this feature in the reconstruction (usually a consequence of low-occupancy and/or incoherent averaging), indicates that the helical ordering of the glycoprotein spikes is coordinated by, but not congruent with the underlying lattice of matrix proteins. The most likely explanation of this anomaly is that the helical array of glycoprotein spikes is coordinated by every third $(1,1)$ helical strand (and less frequently by every second or fourth strand). Whether this phenomenon is simply a consequence of steric collision preventing association of a glycoprotein spike with every M-dimer, or an allosteric mechanism whereby binding of a glycoprotein spike to one matrix dimer favours binding to 
bioRxiv preprint doi: https://doi.org/10.1101/2021.08.04.455049; this version posted August 13,2021 . The copyright holder for this preprint (which was not certified by peer review) is the author/funder, who has granted bioRxiv a license to display the preprint in perpetuity. It is made available under aCC-BY-NC-ND 4.0 International license.

successive dimers on the same strand, or prevents binding on adjacent strands, remains to be determined. It may even be the case that the underlying interaction between $M$ and M2-1 regulates the interaction between $\mathrm{M}$ and the cytoplasmic tails of the glycoproteins.

Intriguingly we have found that glycoprotein spikes tend to cluster in pairs. This finding may have considerable implications for our understanding of both viral attachment and entry processes, as well as epitope presentation and vaccine design. Further investigation targeting the structure of paired glycoprotein spikes will be necessary to establish whether they comprise F-F, G-G or F-G clusters, and whether clustering is coordinated by $\mathrm{M}$, or an intrinsic property of the glycoprotein spikes. The spacing of glycoprotein spikes in doublets on filamentous virions was measured at $84 \AA$, whereas the spacing of M-dimers along the low-pitch helix measured $82 \AA$. Thus, doublet formation may be coordinated by M packing, the slightly larger spacing being a consequence of the measurements being made at a higher radius. Sub-tomogram averaging using masks to target both the glycoprotein spikes and $\mathrm{M}$ from tomograms of virions that have very well-ordered glycoproteins may therefore provide a more detailed view of the interaction between M-dimers and the cytoplasmic tails of glycoproteins and confirm whether $\mathrm{M}$ coordinates glycoprotein spike doublet formation as well as helical packing.

In addition to helical ordering of glycoprotein spikes with doublet formation, we also observed formation of an alternate lattice of glycoprotein spikes, seen on a large pleomorphic virion. Measurements of this array indicated closer packing of spikes (74 $\AA$ ), although the analysis was subject to greater ambiguity, owing to the less sharply resolved density. It would be interesting to establish whether this mode of packing reflects ordering of glycoprotein spikes at the plasma membrane and whether it too is coordinated by $\mathrm{M}$. It has previously been shown that $\mathrm{M}$ is critical for the formation of filaments but not nucleation of budding sites ${ }^{45}$. Association of $\mathrm{M}$ with detergent-resistant lipid microdomains (thought to be the sites of virion assembly) has been shown to depend on glycoprotein expression ${ }^{46,47}$. Confocal microscopy showed the presence of $\mathrm{M}$ protein in inclusion bodies and at the cytoplasmic side of the host-cell plasma membrane ${ }^{47}$. One possible interpretation of the honeycomb-like packing of glycoprotein spikes may be that they (and possibly also $\mathrm{M}$ ) have the potential to pack in a fullerene-like manner at the plasma membrane, fostering the formation of hemispherical caps. Filament elongation might then be driven by assembly of the helical M-dimer lattice, polymerising along the low-pitch helix and engaging the cytoplasmic tails of $F$ and $G$ to form the membraneenclosed helically ordered virions we have observed. Further studies employing cryo-ET of RSV budding sites may define more precisely the ordering of envelope associated proteins and glycoproteins at the plasma membrane and thereby inform our understanding of virion morphogenesis.

\section{Summary}

In the present study, we have used a range of cryogenic electron microscopy and image analysis approaches to characterise the structures of RSV filamentous virions. In so doing we have shown that RSV packages large quantities of N-RNA rings as well as full-length genome containing nucleocapsids. We have provided a detailed description of the viral envelope, in which we discerned the packing of M-dimers, describing how they are oriented relative to the inner-leaflet of the viral envelope and how they are ordered to form a helical array. Furthermore, we show that the helical packing of M-dimers coordinates helical ordering of viral glycoprotein spikes and that the spikes have a propensity to form doublets, a feature that may also be coordinated by M. Finally, we have described an alternate packing of glycoprotein spikes that may be important for virion morphogenesis.

Our findings indicate that future structural analyses have the potential to provide detailed insights into glycoprotein-matrix interactions that drive virion morphogenesis, information that may lead to interventions to treat RSV disease. Moreover, our discovery of extensive ordering of viral glycoproteins has implications for our understanding of the mechanisms of virus attachment and entry and may inform the design of more effective antigens for improved vaccines to prevent RSV disease. 
bioRxiv preprint doi: https://doi org/101101/2021.08.04.455049; this version posted August 13, 2021. The copyright holder for this preprint (which was not certified by peer review) is the author/funder, who has granted bioRxiv a license to display the preprint in perpetuity. It is made available under aCC-BY-NC-ND 4.0 International license.

\section{Methods}

Confocal microscopy

Vero cells were grown in Dulbecco's modified eagle medium (DMEM, Gibco, Life Technologies, UK) supplemented with $10 \%$ foetal bovine serum (FBS; Gibco, Life Technologies) at $37^{\circ} \mathrm{C}$ in an atmosphere containing $5 \% \mathrm{CO} 2$. Monolayers grown to $75 \%$ confluency on glass cover slips were infected with Human Respiratory Syncytial Virus (strain A2 - RSV) at a multiplicity of infection (MOI) of 0.5 for 1 hour and then washed, replacing the media with DMEM containing 2\% FBS. At 24-, 48- and 72-hour time-points, cells were fixed in $4 \%$ formaldehyde and $2.5 \%$ Triton X-100 in PBSA, a blocking step of incubation with sheep serum for 1 hour was followed by immunostaining for $\mathrm{N}$ using a mouse monoclonal antibody (aN009 ${ }^{48}$ ) and detected using a sheep anti-mouse FITC conjugate (Sigma, UK). Phalloidin Alexa Fluor 568 (Invitrogen, UK) was used to stain actin. Cells were mounted using ProLong Antifade plus DAPI reagent (Invitrogen, UK). Imaging was carried out with the Zeiss LSM710 laser scanning confocal microscope.

\section{Propagation of RSV on cryoEM grids}

U2-OS or A549 cells were seeded on to cryoEM grids as follows. Freshly glow-discharged finder gold quantifoil grids (200 mesh R2/2 - Quantifoil MicroTools $\mathrm{GmbH}$, Germany) were sterilized in $70 \% \mathrm{EtOH}$ and placed in a glass-bottomed MatTek dish (MatTek Corporation, MA, USA). $200 \mu \mathrm{l}$ of laminin (50 $\mu \mathrm{g} \mathrm{ml}^{-1}$ ) was added and incubated overnight. Grids were then washed in DMEM. $10^{5}$ cells were added in $2 \mathrm{ml}$ of DMEM supplemented with $10 \%$ FBS and incubated at $37^{\circ} \mathrm{C}$ in an atmosphere containing $5 \% \mathrm{CO} 2$ overnight before infection. Cells were infected with RSV at a MOI of 1 and incubated for a further 72 hours before being prepared for cryoEM. Grids were frozen for cryoEM by plunge freezing. Briefly, $3 \mu$ of a suspension of $5 \mathrm{~nm}$ colloidal gold beads were pipetted onto each grid (BBI Solutions, United Kingdom). Grids were then transferred to a Vitrobot Mk IV (Thermo-Fisher Scientific), blotted for four seconds and then immediately plunged into a bath of liquid ethane.

\section{Imaging - projection images}

RSV virions were initially imaged on a JEOL 2200 FS equipped with a Gatan 914 side-entry cryostage and a Gatan Ultrascan 4000 CCD detector, operated at $200 \mathrm{keV}$. Energy filtered images were recorded with a slit-width of $10 \mathrm{eV}$ at $50 \mathrm{k} \times$ magnification, corresponding to a pixel size of $2.2 \AA$. To improve the quality of images collected we sought access to a $300 \mathrm{keV}$ cryomicroscope equipped with a direct-detection camera. Further cryo-EM was therefore performed at the MRC - Laboratory of Molecular Biology on a Thermo-Fisher Scientific Titan Krios microscope equipped with a Falcon II detector. The microscope was operated at a nominal magnification of $29 \mathrm{k} \times$ giving a calibrated pixel size of $2.84 \AA$ at the specimen scale. Micrographs were recorded as movies, comprising 70 individual frames and with a dose per frame of 1 electron $/ \AA^{2}$ and at 18 frames per second.

\section{Imaging - tomography}

Initial tomography experiments were performed on a JEOL $2200 \mathrm{FS}$, as noted above. Continuous tilt-series were collected, using SerialEM, from $-60^{\circ}$ to $+60^{\circ}$ at $2^{\circ}$ intervals and at a nominal magnification of $20 \mathrm{k} \times$, corresponding to an unbinned pixel size of $5.32 \AA$ at the specimen scale. Improved tomography data, suitable for sub-tomogram averaging were then collected at the UK electron bioimaging centre at Diamond Light Source $(\mathrm{eBIC})$ on a Thermo-Fisher Scientific Titan Krios microscope equipped with a Gatan BioQuantum K2 energy filtered direct detection camera. Dose-symmetric tilt-series collection was performed using SerialEM 49,50. Energy-filtered images were collected with a slit-width of $20 \mathrm{eV}$ and an applied defocus of between -2 and $-4.5 \mu \mathrm{m}$. One second exposures were recorded with an electron exposure of 2 electrons $/ \AA^{2}$, partitioned over five movie frames. A total of 41 images were recorded per tilt-series at $3^{\circ}$ intervals from $-60^{\circ}$ to $+60^{\circ}$, thus a total exposure of 82 electrons $/ \AA^{2}$ was applied per tilt-series. Tilt-series were recorded at a nominal column magnification of $81 \mathrm{k} \times$ corresponding to a calibrated pixel size of $1.79 \AA$ at the specimen scale.

\section{Fourier analysis}

Preliminary data collected on the JEOL 2200 FS were processed to determine the presence of helical layer lines using SPIDER ${ }^{51}$. Briefly, overlapping sections of a single filamentous virion were extracted. The log of the power spectrum for each image section was calculated. The power spectra were then summed. Higherquality data collected at $300 \mathrm{keV}$ and using a direct electron detection camera were visualised using Ximdisp 52. Indexing was performed using PyHI (personal communication Prof. Xuewu Zhang UT Southwestern 
bioRxiv preprint doi: https://doi.org/10.1101/2021.08.04.455049; this version posted August 13, 2021. The copyright holder for this preprint (which was not certified by peer review) is the author/funder, who has granted bioRxiv a license to display the preprint in perpetuity. It is made available under aCC-BY-NC-ND 4.0 International license.

medical centre). Fourier synthesis was used to produce a filtered image of the helical components by assigning crystallographic indices to pairs of reflections in the Fourier transform. The image was reconstituted by masking and inverse Fourier transformation using trmask, a program within the MRC image processing software suite ${ }^{53}$.

\section{Tomogram calculation}

Individual movies were corrected for drift and beam induced motion using MotionCor2 ${ }^{54}$. Motion corrected images were then compiled into an angle ordered stack file using a perl script to extract the correct files and tilt angles from the SerialEM metadata files (mdoc), creating the final tilt-series using the IMOD command newstack ${ }^{55}$. Tilt-series alignment and reconstruction by weighted back projection was then accomplished using the IMOD package. Defocus estimation was performed using CTFFIND4 ${ }^{56}$. For visualisation and interpretation tomograms were binned by a factor of four and then denoised using the denoise $3 \mathrm{~d}$ option in Topaz ${ }^{57}$.

\section{Sub-tomogram averaging}

Tomograms were recalculated with a SIRT-like filter (50 iterations) and $8 \times$ binning to assist in filament axis definition and particle picking in Dynamo ${ }^{35,58}$. A catalogue was created with 10 tomograms containing 11 filamentous RSV virions. Sub-tomogram/particle coordinates were defined along the filaments using the 'crop on rings along path' model in Dynamo. From the 10 tomograms, 30,088 sub-tomograms were extracted from the oversampled coordinates in a box size of 32 voxels, oriented normal to the filament/viral envelope. An initial average was calculated and smeared along the filament major axis to produce a featureless reference. More accurate sub-tomogram positions were calculated by running an alignment project with the featureless reference and allowing shifts only in the $z$ direction to locate the precise position of the viral envelope.

Sub-tomograms were aligned to a smeared and low pass filtered reference while allowing angular and rotational searches of $15^{\circ}$ with $5^{\circ}$ sampling. Shifts of 4,4 and 1 pixels were permitted in $X, Y$ and $Z$ directions, respectively. Initial alignments were performed with a wide saddle shaped mask (to exclude density from the viral envelope and M2-1 layers) followed by a tighter mask. Upon completion of the alignment projects, the sub-tomograms were re-centred in the extraction boxes based on the improved coordinates and extracted from tomograms with a reduced level of binning i.e. $4 \times, 2 \times$ and $1 \times$ binning. 15 alignment iterations were performed at each binning level. The averaging and alignment protocols were repeated for each reduced level of binning with an increasing box size until unbinned averages were attained (in a $256^{3}$ box). For the final alignment step, sub-tomograms were extracted from tomograms calculated using weighted back-projection (i.e., omitting the SIRT-like filter). Half-maps were generated and compared using the Relion post-processing and local-resolution tests ${ }^{59}$. A FSC cut off of 0.5 was adopted to measure the resolution of the map for the M-layer using a saddle shaped mask. Averages were visualised and X-ray structures were fitted in UCSF Chimera and ChimeraX ${ }^{60,61}$.

\section{Acknowledgements}

The authors wish to thank Drs. Greg McMullan and Kutti R Vinothkumar for support with data collection at the LMB. We thank Diamond Light Source for access to the Cryo-EM facilities at the UK national electron bioimaging centre (eBIC), proposal EM16637-5, funded by the Wellcome Trust, MRC and BBSRC. We are indebted to Daniel Clare for his expert assistance during dosesymmetric tomography data collection at eBIC.

This work was supported by the United Kingdom Medical Research Council (MC_UU_12014/7 to DB; MR/M000451/ for DB, RF, MJC, JS and SEB; MC-A025-5PL41 for MS). RF, DB and AMB were supported by the United States of America National Institutes of Health (1R01AI113321), BJP and HJ were supported by a Wellcome doctoral training programme (102463/Z/13/Z and 099786/Z/12/Z respectively)
The MRC-University of Glasgow Centre for Virus Research uses the CRediT taxonomy of author contributions. MJC - formal analysis, writing - review, JMS - formal analysis, methodology, writing - original draft, JH - methodology, writing - review, AMB - investigation, JS - investigation, SEB - investigation, MS - formal analysis, writing review, BJP - investigation, writing - original draft, HJ - investigation, GZ - methodology, writing - review RF conceptualisation, funding acquisition, writing - original draft, SV - investigation, methodology, supervision, DB - conceptualisation, methodology, investigation, formal analysis, funding acquisition, supervision, visualisation, writing - original draft.

\section{Data deposition}

The sub-tomogram average described in this paper and a representative tomogram have been deposited in the electron microscopy data bank - accession number EMD $* * * * *$ 
bioRxiv preprint doi: https://doi.org/10.1101/2021.08.04.455049; this version posted August 13, 2021. The copyright holder for this preprint (which was not certified by peer review) is the author/funder, who has granted bioRxiv a license to display the preprint in perpetuity. It is made available under aCC-BY-NC-ND 4.0 International license.

\section{References}

1 Shi, T. et al. Global, regional, and national disease burden estimates of acute lower respiratory infections due to respiratory syncytial virus in young children in 2015: a systematic review and modelling study. Lancet 390, 946-958, doi:10.1016/S0140-6736(17)30938-8 (2017).

2 Ackerson, B. et al. Severe Morbidity and Mortality Associated With Respiratory Syncytial Virus Versus Influenza Infection in Hospitalized Older Adults. Clin Infect Dis 69, 197-203, doi:10.1093/cid/ciy991 (2019).

$3 \quad$ Kwon, Y. S. et al. Risk of mortality associated with respiratory syncytial virus and influenza infection in adults. BMC Infect Dis 17, 785, doi:10.1186/s12879-017-2897-4 (2017).

4 Rima, B. et al. ICTV Virus Taxonomy Profile: Pneumoviridae. J Gen Viro/ 98, 2912-2913, doi:10.1099/ jgv.0.000959 (2017).

5 van den Hoogen, B. G. et al. A newly discovered human pneumovirus isolated from young children with respiratory tract disease. Nat Med 7, 719-724, doi:10.1038/89098 (2001).

6 Bakker, S. E. et al. The respiratory syncytial virus nucleoprotein-RNA complex forms a left-handed helical nucleocapsid. J Gen Viro/ 94, 1734-1738, doi:10.1099/vir.0.053025-0 (2013).

Tawar, R. G. et al. Crystal structure of a nucleocapsid-like nucleoprotein-RNA complex of respiratory syncytial virus. Science 326, 1279-1283, doi:10.1126/science.1177634 (2009). Galloux, M. et al. Minimal Elements Required for the Formation of Respiratory Syncytial Virus Cytoplasmic Inclusion Bodies In Vivo and In Vitro. mBio 11, doi:10.1128/mBio.01202-20 (2020). Norrby, E., Marusyk, H. \& Orvell, C. Morphogenesis of respiratory syncytial virus in a green monkey kidney cell line (Vero). J Virol 6, 237-242, doi:10.1128/JVI.6.2.237-242.1970 (1970).

10 Gilman, M. S. A. et al. Structure of the Respiratory Syncytial Virus Polymerase Complex. Cell 179, 193-204 e114, doi:10.1016/j.cell.2019.08.014 (2019).

11 Bermingham, A. \& Collins, P. L. The M2-2 protein of human respiratory syncytial virus is a regulatory factor involved in the balance between RNA replication and transcription. Proc Natl Acad Sci U S A 96, 11259-11264, doi:10.1073/pnas.96.20.11259 (1999).

12 Fearns, R. \& Collins, P. L. Role of the M2-1 transcription antitermination protein of respiratory syncytial virus in sequential transcription. J Virol 73, 5852-5864, doi:10.1128/JVI.73.7.5852-5864.1999 (1999).

13 Kiss, G. et al. Structural analysis of respiratory syncytial virus reveals the position of M2-1 between the matrix protein and the ribonucleoprotein complex. J Virol 88, 7602-7617, doi:10.1128/JVI.0025614 (2014).

14 Liljeroos, L., Krzyzaniak, M. A., Helenius, A. \& Butcher, S. J. Architecture of respiratory syncytial virus revealed by electron cryotomography. Proc Natl Acad Sci U S A 110, 11133-11138, doi:10.1073/ pnas.1309070110 (2013).

15 Forster, A., Maertens, G. N., Farrell, P. J. \& Bajorek, M. Dimerization of matrix protein is required for budding of respiratory syncytial virus. J Virol 89, 4624-4635, doi:10.1128/JVI.03500-14 (2015).

16 Leyrat, C., Renner, M., Harlos, K., Huiskonen, J. T. \& Grimes, J. M. Structure and self-assembly of the calcium binding matrix protein of human metapneumovirus. Structure 22, 136-148, doi:10.1016/j. str.2013.10.013 (2014).

17 Money, V. A., McPhee, H. K., Mosely, J. A., Sanderson, J. M. \& Yeo, R. P. Surface features of a Mononegavirales matrix protein indicate sites of membrane interaction. Proc Natl Acad Sci U S A 106, 4441-4446, doi:10.1073/pnas.0805740106 (2009).

18 McLellan, J. S. et al. Structure of RSV fusion glycoprotein trimer bound to a prefusion-specific neutralizing antibody. Science 340, 1113-1117, doi:10.1126/science.1234914 (2013).

19 McLellan, J. S., Yang, Y., Graham, B. S. \& Kwong, P. D. Structure of respiratory syncytial virus fusion glycoprotein in the postfusion conformation reveals preservation of neutralizing epitopes. $J$ Virol 85, 7788-7796, doi:10.1128/JVI.00555-11 (2011).

20 Leyrat, C., Renner, M., Harlos, K., Huiskonen, J. T. \& Grimes, J. M. Drastic changes in conformational dynamics of the antiterminator M2-1 regulate transcription efficiency in Pneumovirinae. Elife 3, e02674, doi:10.7554/eLife.02674 (2014).

21 Selvaraj, M. et al. The Structure of the Human Respiratory Syncytial Virus M2-1 Protein Bound to the Interaction Domain of the Phosphoprotein P Defines the Orientation of the Complex. mBio 9, doi:10.1128/mBio.01554-18 (2018). 
bioRxiv preprint doi: https://doi.org/10.1101/2021.08.04.455049; this version posted August 13,2021 . The copyright holder for this preprint (which was not certified by peer review) is the author/funder, who has granted bioRxiv a license to display the preprint in perpetuity. It is made available under aCC-BY-NC-ND 4.0 International license.

(2020).

$23 \mathrm{Li}, \mathrm{T}$. et al. The shape of pleomorphic virions determines resistance to cell-entry pressure. Nat Microbiol 6, 617-629, doi:10.1038/s41564-021-00877-0 (2021).

24 Vahey, M. D. \& Fletcher, D. A. Influenza A virus surface proteins are organized to help penetrate host mucus. Elife 8, doi:10.7554/eLife.43764 (2019).

25 Kuppan, J. P., Mitrovich, M. D. \& Vahey, M. D. A morphological transformation in respiratory syncytial virus leads to enhanced complement activation. bioRxiv, 2021.2005.2006.442421, doi:10.1101/2021.05.06.442421 (2021).

26 Bachi, T. \& Howe, C. Morphogenesis and ultrastructure of respiratory syncytial virus. J Virol 12, 11731180, doi:10.1128/JVI.12.5.1173-1180.1973 (1973).

27 Vijayakrishnan, S. et al. Cryotomography of budding influenza A virus reveals filaments with diverse morphologies that mostly do not bear a genome at their distal end. PLoS Pathog 9, e1003413, doi:10.1371/journal.ppat.1003413 (2013).

He, S. \& Scheres, S. H. W. Helical reconstruction in RELION. J Struct Bio/ 198, 163-176, doi:10.1016/j. jsb.2017.02.003 (2017).

Diaz, R., Rice, W. J. \& Stokes, D. L. Fourier-Bessel reconstruction of helical assemblies. Methods Enzymol 482, 131-165, doi:10.1016/S0076-6879(10)82005-1 (2010).

$\mathrm{Ke}, \mathrm{Z}$. et al. The Morphology and Assembly of Respiratory Syncytial Virus Revealed by Cryo-Electron Tomography. Viruses 10, doi:10.3390/v10080446 (2018).

31 Bhella, D., Ralph, A., Murphy, L. B. \& Yeo, R. P. Significant differences in nucleocapsid morphology within the Paramyxoviridae. J Gen Virol 83, 1831-1839, doi:10.1099/0022-1317-83-8-1831 (2002).

Loney, C., Mottet-Osman, G., Roux, L. \& Bhella, D. Paramyxovirus ultrastructure and genome packaging: cryo-electron tomography of sendai virus. J Virol 83, 8191-8197, doi:10.1128/JVI.0069309 (2009).

33 Tran, T. L. et al. The nine C-terminal amino acids of the respiratory syncytial virus protein $\mathrm{P}$ are necessary and sufficient for binding to ribonucleoprotein complexes in which six ribonucleotides are contacted per N protein protomer. J Gen Virol 88, 196-206, doi:10.1099/vir.0.82282-0 (2007).

Maclellan, K., Loney, C., Yeo, R. P. \& Bhella, D. The 24-angstrom structure of respiratory syncytial virus nucleocapsid protein-RNA decameric rings. J Virol 81, 9519-9524, doi:10.1128/JVI.00526-07 (2007).

35 Castano-Diez, D., Kudryashev, M., Arheit, M. \& Stahlberg, H. Dynamo: a flexible, user-friendly development tool for subtomogram averaging of cryo-EM data in high-performance computing environments. J Struct Biol 178, 139-151, doi:10.1016/j.jsb.2011.12.017 (2012).

Alayyoubi, M., Leser, G. P., Kors, C. A. \& Lamb, R. A. Structure of the paramyxovirus parainfluenza virus 5 nucleoprotein-RNA complex. Proc Natl Acad Sci U S A 112, E1792-1799, doi:10.1073/ pnas.1503941112 (2015).

37 Albertini, A. A. et al. Crystal structure of the rabies virus nucleoprotein-RNA complex. Science 313, 360-363, doi:10.1126/science.1125280 (2006).

Braun, M. R. et al. RNA elongation by respiratory syncytial virus polymerase is calibrated by conserved region V. PLoS Pathog 13, e1006803, doi:10.1371/journal.ppat.1006803 (2017).

Noton, S. L., Deflube, L. R., Tremaglio, C. Z. \& Fearns, R. The respiratory syncytial virus polymerase has multiple RNA synthesis activities at the promoter. PLoS Pathog 8, e1002980, doi:10.1371/journal. ppat.1002980 (2012).

40 Tremaglio, C. Z., Noton, S. L., Deflube, L. R. \& Fearns, R. Respiratory syncytial virus polymerase can initiate transcription from position 3 of the leader promoter. $J$ Virol 87, 3196-3207, doi:10.1128/ JVI.02862-12 (2013).

41 Gao, Y. et al. In vitro trackable assembly of RNA-specific nucleocapsids of the respiratory syncytial virus. J Biol Chem 295, 883-895, doi:10.1074/jbc.RA119.011602 (2020).

42 Rincheval, V. et al. Functional organization of cytoplasmic inclusion bodies in cells infected by respiratory syncytial virus. Nat Commun 8, 563, doi:10.1038/s41467-017-00655-9 (2017).

43 Roden, C. \& Gladfelter, A. S. RNA contributions to the form and function of biomolecular condensates. Nat Rev Mol Cell Biol 22, 183-195, doi:10.1038/s41580-020-0264-6 (2021).

44 Hanley, L. L. et al. Roles of the respiratory syncytial virus trailer region: effects of mutations on genome production and stress granule formation. Virology 406, 241-252, doi:10.1016/j.virol.2010.07.006 (2010). 
bioRxiv preprint doi: https://doi org/101101/2021.08.04 455049; this version posted August 13, 2021. The copyright holder for this preprint (which was not certified by peer review) is the author/funder, who has granted bioRxiv a license to display the preprint in perpetuity. It is made available under aCC-BY-NC-ND 4.0 International license.

Mitra, R., Baviskar, P., Duncan-Decocq, R. R., Patel, D. \& Oomens, A. G. The human respiratory syncytial virus matrix protein is required for maturation of viral filaments. J Virol 86, 4432-4443, doi:10.1128/JVI.06744-11 (2012).

Henderson, G., Murray, J. \& Yeo, R. P. Sorting of the respiratory syncytial virus matrix protein into detergent-resistant structures is dependent on cell-surface expression of the glycoproteins. Virology 300, 244-254, doi:10.1006/viro.2002.1540 (2002).

47 Marty, A., Meanger, J., Mills, J., Shields, B. \& Ghildyal, R. Association of matrix protein of respiratory syncytial virus with the host cell membrane of infected cells. Arch Virol 149, 199-210, doi:10.1007/ s00705-003-0183-9 (2004).

48 Murray, J., Loney, C., Murphy, L. B., Graham, S. \& Yeo, R. P. Characterization of monoclonal antibodies raised against recombinant respiratory syncytial virus nucleocapsid $(\mathrm{N})$ protein: identification of a region in the carboxy terminus of $\mathrm{N}$ involved in the interaction with $\mathrm{P}$ protein. Virology 289, 252-261, doi:10.1006/viro.2001.1150 (2001).

49 Mastronarde, D. N. Automated electron microscope tomography using robust prediction of specimen movements. J Struct Biol 152, 36-51, doi:10.1016/j.jsb.2005.07.007 (2005).

50 Hagen, W. J. H., Wan, W. \& Briggs, J. A. G. Implementation of a cryo-electron tomography tilt-scheme optimized for high resolution subtomogram averaging. J Struct Biol 197, 191-198, doi:10.1016/j. jsb.2016.06.007 (2017).

51 Frank, J. et al. SPIDER and WEB: processing and visualization of images in 3D electron microscopy and related fields. J Struct Biol 116, 190-199, doi:10.1006/jsbi.1996.0030 (1996).

52 Smith, J. M. Ximdisp--A visualization tool to aid structure determination from electron microscope images. J Struct Biol 125, 223-228, doi:10.1006/jsbi.1998.4073 (1999).

53 Crowther, R. A., Henderson, R. \& Smith, J. M. MRC image processing programs. J Struct Biol 116, 9-16, doi:10.1006/jsbi.1996.0003 (1996).

54 Zheng, S. Q. et al. MotionCor2: anisotropic correction of beam-induced motion for improved cryoelectron microscopy. Nat Methods 14, 331-332, doi:10.1038/nmeth.4193 (2017).

Kremer, J. R., Mastronarde, D. N. \& McIntosh, J. R. Computer visualization of three-dimensional image data using IMOD. J Struct Biol 116, 71-76, doi:10.1006/jsbi.1996.0013 (1996).

Rohou, A. \& Grigorieff, N. CTFFIND4: Fast and accurate defocus estimation from electron micrographs. J Struct Biol 192, 216-221, doi:10.1016/j.jsb.2015.08.008 (2015).

Bepler, T., Kelley, K., Noble, A. J. \& Berger, B. Topaz-Denoise: general deep denoising models for cryoEM and cryoET. Nat Commun 11, 5208, doi:10.1038/s41467-020-18952-1 (2020).

58 Castano-Diez, D., Kudryashev, M. \& Stahlberg, H. Dynamo Catalogue: Geometrical tools and data management for particle picking in subtomogram averaging of cryo-electron tomograms. J Struct Biol 197, 135-144, doi:10.1016/j.jsb.2016.06.005 (2017).

59 Scheres, S. H. RELION: implementation of a Bayesian approach to cryo-EM structure determination. J Struct Biol 180, 519-530, doi:10.1016/j.jsb.2012.09.006 (2012).

60 Pettersen, E. F. et al. UCSF Chimera--a visualization system for exploratory research and analysis. $J$ Comput Chem 25, 1605-1612, doi:10.1002/jcc.20084 (2004).

61 Pettersen, E. F. et al. UCSF ChimeraX: Structure visualization for researchers, educators, and developers. Protein Sci 30, 70-82, doi:10.1002/pro.3943 (2021). 